\title{
Integration of computational modeling and experimental techniques to design fuel surrogates
}

Choudhury, H.A.; Intikhab, S.; Kalakul, Sawitree; Gani, Rafiqul; Elbashir, N.O.

Published in:

Journal of Natural Gas Science \& Engineering

Link to article, DOI:

10.1016/j.jngse.2017.07.025

Publication date:

2018

Document Version

Peer reviewed version

Link back to DTU Orbit

\section{Citation (APA):}

Choudhury, H. A., Intikhab, S., Kalakul, S., Gani, R., \& Elbashir, N. O. (2018). Integration of computational modeling and experimental techniques to design fuel surrogates. Journal of Natural Gas Science \& Engineering, 55, 585-594. https://doi.org/10.1016/j.jngse.2017.07.025

\section{General rights}

Copyright and moral rights for the publications made accessible in the public portal are retained by the authors and/or other copyright owners and it is a condition of accessing publications that users recognise and abide by the legal requirements associated with these rights.

- Users may download and print one copy of any publication from the public portal for the purpose of private study or research.

- You may not further distribute the material or use it for any profit-making activity or commercial gain

- You may freely distribute the URL identifying the publication in the public portal 


\section{Accepted Manuscript}

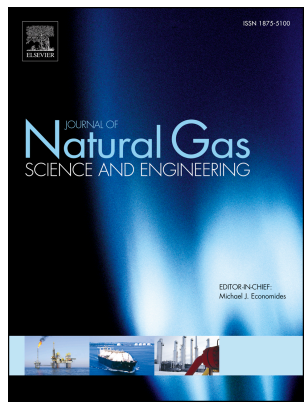

Integration of computational modeling and experimental techniques to design fuel surrogates

H.A. Choudhury, S. Intikhab, S. Kalakul, R. Gani, N.O. Elbashir

PII: $\quad$ S1875-5100(17)30322-0

DOI: $\quad$ 10.1016/j.jngse.2017.07.025

Reference: JNGSE 2266

To appear in: Journal of Natural Gas Science and Engineering

Received Date: 9 January 2017

Revised Date: 13 July 2017

Accepted Date: 16 July 2017

Please cite this article as: Choudhury, H.A., Intikhab, S., Kalakul, S., Gani, R., Elbashir, N.O., Integration of computational modeling and experimental techniques to design fuel surrogates, Journal of Natural Gas Science \& Engineering (2017), doi: 10.1016/j.jngse.2017.07.025.

This is a PDF file of an unedited manuscript that has been accepted for publication. As a service to our customers we are providing this early version of the manuscript. The manuscript will undergo copyediting, typesetting, and review of the resulting proof before it is published in its final form. Please note that during the production process errors may be discovered which could affect the content, and all legal disclaimers that apply to the journal pertain. 


\title{
Integration of Computational Modeling and Experimental Techniques to Design Fuel Surrogates
}

\author{
H. A. Choudhury ${ }^{a}$, S. Intikhab ${ }^{a}$, S. Kalakul ${ }^{b}$, , R. Gani ${ }^{b}$ and N.O. Elbashir ${ }^{a, c^{*}}$ \\ ${ }^{a}$ Chemical Engineering Program and Petroleum Engineering Program, Texas A\&M University at Qatar, 23874 \\ Doha, Qatar \\ ${ }^{b}$ Department of Chemical and Biochemical Engineering Program, Technical University of Denmark, DK-2800 \\ Lyngby, Denmark \\ ${ }^{a}$ TEES Gas \& Fuels Research Center, Texas A\&M University at Qatar, 23874 Doha, Qatar
}

* Corresponding author: Nimir.elbashir@qatar.tamu.edu

Keywords: Fuel surrogates, Gasoline blend, , GC-DHA, Additives, Alternative Fuel, GTL

\begin{abstract}
Conventional gasoline comprises of a large number of hydrocarbons that makes it difficult to utilize in a model for prediction of its properties. Modeling is needed for a better understanding of the fuel flow and combustion behavior that are essential to enhance fuel quality and improve engine performance. A simplified alternative is to develop surrogate fuels that have fewer compounds and emulate certain important desired physical properties of the target fuels. Six gasoline blends were formulated through a computer aided model based technique "Mixed Integer Non-Linear Programming" (MINLP). Different target properties of the surrogate blends for example, Reid vapor pressure $(R V P)$, dynamic viscosity $(\eta)$, density $(\rho)$, Research octane number $(R O N)$ and liquid-liquid miscibility of the surrogate blends) were calculated. In this study, more rigorous property models in a computer aided tool called Virtual ProcessProduct Design Laboratory (VPPD-Lab) are applied onto the defined compositions of the surrogate gasoline. The aim is to primarily verify the defined composition of gasoline by means of VPPD-Lab. $\rho, \eta$ and $R V P$ are calculated with more accuracy and constraints such as distillation curve and flash point on the blend design are also considered. A post-design experiment-based verification step is proposed to further improve and fine-tune the "best" selected gasoline blends following the computation work. Here, advanced experimental techniques are used to measure the $R V P, \rho, \eta, R O N$ and distillation temperatures. The experimental results are compared with the model predictions as well as the extended calculations in VPPD-Lab.
\end{abstract}


1

\section{Introduction}

Fuels such as conventional gasoline are complex mixtures of hundreds of hydrocarbons that frequently vary with time and location (Pitz and Mueller, 2011). This complexity makes it extremely difficult to study underlying fundamental processes such as combustion, emission and other physical properties of fuels. Currently, it is not possible to model conventional gasoline through a detailed kinetic model since the kinetics and interactions of all the compounds present in conventional gasolines are not fully understood (Mueller et al., 2012). As a result, a favorable approach to overcoming these problems is the use of surrogate fuels that represent their conventional counterparts but are comprised of a smaller number of organic compounds. In general, a surrogate fuel is one that is composed of a small and diverse number of organic compounds that mimic certain target characteristics of the original fuel (Pitz et al. 2007). Since simulations are frequently performed during modern engine testing and fuel combustion, the simpler composition of the surrogate fuels allow for more efficient simulations (Reiter et al., 2015). Surrogate fuels not only provide a better understanding of the effects of the composition on different desired/undesired properties but also have value as time-invariant reference fuels for experimental studies.

There are several published articles on the generation of surrogate fuels for gasoline (Mueller et al., 2012; Mehl et al., 2011), diesel (Pitz et al., 2007) and jet fuel (Elmalik et al., 2014). Mehl et al. (2011) proposed a liquid blend of $n$-heptane, iso-octane, toluene and 2-pentene in an attempt to match the physical and chemical properties of real non-oxygenated gasoline. They also proposed a simplified kinetic mechanism of fuel combustion in an engine with this four component surrogate fuel, without compromising ignition delay times and flame speeds for a broad range of operating conditions.

In addition to time-invariant reference fuels, surrogates can also be used directly as synthetic fuels. However, to enhance the surrogate's physicochemical properties and reduce consumption, other chemical additives are required. Numerous studies have been performed to identify additives for gasoline (Canakci et al. 2013; Masum et al. 2015; Rodríguez-Antón et al. 2015). Canakci et al. (2013) and Masum et al. (2015) investigated the effects of alcohol blended with gasoline on the exhaust emission of a Spark Ignition (SI) engine. While these studies provided useful knowledge, they were mostly empirical in nature and the application of computational model-based methodologies are now being employed to design/improve products, enabling them to reach the market faster by reducing expensive and timeconsuming experiments (Gani, 2004). In this respect, Conte et al. (2011) proposed a systematic computer aided model-based approach for liquid formulated products such as liquid insect repellents and sun-screen lotion. Yunus et al. (2014) adapted this approach to design blended products such as gasoline, diesel and lubricant blends.

According to the method of Yunus et al. (2014), for gasoline or diesel blends, first the main ingredient (MI) comprising of hydrocarbon building blocks that are representative of the corresponding fuel, are identified. In the next steps, additives are identified and blended with MI to enhance the quality of the surrogate fuel. The blends are formulated based on target properties such as Reid vapor pressure $(R V P)$, flash point $\left(T_{f}\right)$, dynamic viscosity $(\eta)$, density $(\rho)$, research octane number $(R O N)$, heating value $(H H V)$, toxicity $\left(L C_{50}\right)$, oxygen content $\left(W t_{O_{2}}\right)$ and liquid blend miscibility of the surrogate blends. These targeted properties need to be matched to identify the surrogate fuel representing a desired gasoline blend as they represent various aspects of the fuel such as its ability to be burned, its engine efficiency, and its environmental impact. 
In another recent study, Luning Park et al. (2015) report the formulation and development of alcohols-tojet (ATJ) surrogate fuels. They used the physicochemical properties and chemical composition of a conventional jet-fuel to design a surrogate fuel that is comprised of 30 (vol\%) of additives and 70 (vol\%) petroleum JP-5. Several surrogate fuels were prepared to investigate physicochemical properties of the jet-fuel blend. Further, a combustion study was also carried out to investigate the engine performance with the surrogate fuel.

While the experiment based method proposed by Luning Prak et al. (2015) could lead to surrogate fuels with validated target properties, the model-based computer-aided method of Yunus et al. (2014) is able to very quickly search over a wide range of solutions to identify a set of promising blends. Combining this approach with an experiment based approach, it is possible to quickly identify first, a small set of promising alternatives, then, through experiments to subsequently verify and fine-tune them to determine the optimal fuel-blend product. Thus, precious experimental resources are used only for focused experiments to validate and improve the blended product, and not wasted on a blind trial-and-error search. The current study is focused on the experimental verification of the physicochemical properties of the gasoline blends proposed by Yunus et al. (2014), and, based on the measured properties to further finetune and improve the blends. Also, the model-based framework is extended with an improved set of property models. This paper is organized as follows: in Section 2, Surrogate composition prediction via VPPD-lab is described. In Section 3, the methods needed to prepare the surrogate fuels and experimentally verify their composition and physicochemical properties are described. In Section 4, the compositional verification is discussed, followed by a comparison of the experimental results of RON, $R V P, \eta$ and $\rho$ with the VPPD-Lab-predicted values to evaluate the effectiveness of the model used, to improve its predictability and to fine-tune the surrogate fuel compositions.

\section{Blend composition prediction via VPPD-Lab}

Recent efforts have investigated the integration of model-based methodologies into a computer-aided framework as a chemical product design and evaluation software called the Virtual Process-Product Design Laboratory (VPPD-Lab) (Kalakul et al., 2015). VPPD-Lab allows users to; (1) analyze chemicalbased products by performing virtual experiments (product property and performance calculations); (2) predict the properties of products; and (3) create new product property and product performance models when needed. However, unlike process simulators, VPPD-Lab can also be used directly for (4) design of chemicals based products using design templates for various types of products, such as single molecule products, formulations, blends, emulsions and devices; and, (5) to create new product design templates when the needed template for the desired product is not available. VPPD-Lab employs a suite of algorithms (such as database search, molecular and mixture blend design) and tool boxes (such as property calculations and property model consistency tests) for specific product property prediction, design, and/or analysis tasks. Within VPPD-Lab, the extended methodology of Yunus et al. (2014) has been implemented so that many blended chemical products can be designed and evaluated in terms of their target properties. The property models used for the design and evaluation of gasoline blends are given in Appendix.

Conventional gasoline is comprised of a vast number of hydrocarbons, and for a better understanding of fuel behavior in the combustion engine, a set of properties need to be analyzed. In this section, the five gasoline surrogates plus a conventional gasoline (main ingredient) reported by Yunus et al. (2014) are first evaluated using the extended property model library of VPPD-Lab. The five surrogates are obtained by blending the main ingredient (MI), which represents the conventional gasoline, with additives to obtain tailor-made gasoline blends (surrogate fuels) that have properties better than the MI. The five gasoline 
blends should have better fuel performance and meet or exceed stringent requirements for worldwide fuel handling and gasoline standards as listed in Table 1.

3

4

Table 1: Gasoline needs to be translated target properties

\begin{tabular}{lll}
\hline Need & Target Property & Target Value \\
\hline Ability to be burned & Reid vapor pressure $(\mathrm{kPa})$ & $45 \leq \mathrm{RVP} \leq 60$ \\
Flammability & Flash point $(\circ \mathrm{C})$ & $\mathrm{T}_{\mathrm{f}} \leq 27$ \\
Engine efficiency & Higher heating value $(\mathrm{MJ} / \mathrm{kg})$ & $\mathrm{HHV} \geq 35$ \\
& Density at $15 \circ \mathrm{C}(\mathrm{g} / \mathrm{cm} 3)$ & $0.720 \leq \rho \leq 0.775$ \\
& RON & $\mathrm{RON} \geq 92$ \\
Consistency of fuel flow & Dynamic viscosity at $20 \circ \mathrm{C}(\mathrm{cP})$ & $0.30 \leq \eta \leq 0.60$ \\
Liquid blend miscibility & Gibbs energy of mixing $($ Conte et al., 2011$)$ & Trend of $\Delta G^{\text {mix }} / R T$ \\
Environmental impacts & Oxygen content $(\mathrm{wt} \%)$ & $2 \leq \mathrm{Wto} \leq 20$ \\
& -logLC50 (mol/L $)$ & $-\log (\mathrm{LC} 50)<3.08$ \\
\hline
\end{tabular}

5

6 Six chemicals are selected to represent the main ingredient (MI) with the composition given in Table 2. 7 As additives, 22 bio-based organic chemicals from which two are chosen for tailor-made gasoline blends 8 are considered. The blend design problem is formulated as a Mixed Integer Non-Linear Programming 9 (MINLP) problem, where the fuel composition is to be optimized subject to target properties. The identity 10 of the additives are represented by binary integer variables (zero or one) while the compositions of the MI and the additives are the real variables (zero to hundred). The five most promising ternary blends (two additive chemicals and MI) with the minimum conventional gasoline (MI) composition are listed in Table 3 with the predicted target properties values from Yunus et al. (2014).

Table 2: Gasoline surrogate MI composition

\begin{tabular}{cc}
\hline Chemical & Composition (vol \%) \\
\hline Butane & 6.58 \\
n-Heptane & 12.6 \\
Iso-octane & 53.99 \\
1-Pentene & 3.63 \\
Methylcyclopentane & 8.47 \\
Toluene & 14.73 \\
\hline
\end{tabular}

Table 3: Gasoline blend candidates with their composition and properties

\begin{tabular}{|c|c|c|c|c|c|c|c|}
\hline ID & Composition (vol \%) & $\begin{array}{l}\boldsymbol{R} \boldsymbol{V} \boldsymbol{P} \\
(\mathrm{kPa})\end{array}$ & $\begin{array}{c}\boldsymbol{H H} \boldsymbol{V} \\
(\mathrm{MJ} / \mathrm{kg})\end{array}$ & $\begin{array}{c}\boldsymbol{\eta} \\
(\mathrm{cP})\end{array}$ & $\begin{array}{l}\text { Wto }_{2} \\
(\mathrm{wt} \%)\end{array}$ & $\begin{array}{l}-\log L C_{50} \\
(\mathrm{~mol} / \mathrm{L})\end{array}$ & RON \\
\hline Blend 1 & MI(69) THF(11) MeTHF(20) & 46 & 41 & 0.48 & 7.2 & 2.7 & - \\
\hline Blend 2 & $\operatorname{MI}(67) \operatorname{ACE}(13) \operatorname{MeTHF}(20)$ & 46 & 41 & 0.47 & 7.8 & 2.7 & - \\
\hline Blend 3 & $\operatorname{MI}(72) \operatorname{ACE}(10) 2 B E(18)$ & 49 & 40 & 0.48 & 7.3 & 2.7 & - \\
\hline Blend 4 & $\operatorname{MI}(75)$ 2BE(13) MeTHF (12) & 45 & 43 & 0.50 & 5.5 & 2.9 & - \\
\hline Blend 5 & MI(77) $\operatorname{EtOH}(12)$ MeTHF (11) & 45 & 42 & 0.57 & 6.7 & 2.8 & 96 \\
\hline
\end{tabular}

THF: Tetrahydrofuran; MeTHF: Methyl tetrahydrofuran; ACE: Acetone; 2BE: 2-Butanone; EtOH: Ethanol 
Table 5: Mixture
An important issue when using model-based techniques and especially property models, is the question of the accuracy and reliability of the predictions. Therefore, to verify the results of Yunus et al. (2014), the chemicals database and extended predictive models library of VPPD-Lab are used. The properties of interest and their corresponding models are retrieved from the property model library in VPPD-Lab. One such property [not considered by Yunus et al.(2014)] is the distillation profile, which is a set of increasing temperatures at which the fuel evaporates for a fixed series of increasing volume percentages (10 percent (T10), 50 percent (T50) and 90 percent (T90)). In this study, the distillation profile is calculated using the method of Hoffman (Hoffman, 1969) together with the property models in VPPD-Lab. The pure component properties are obtained from the experimental data if they are available or estimated using the models listed in Table 4 . The target mixture property models are given in Table 5 . The calculated results are given in Table 6 (in Section 4.2).

Table 4: Pure component properties models

\begin{tabular}{cc}
\hline Pure component property & Model \\
\hline Higher heating value $\left(H H V_{i}\right)$ & (Yunus et al., 2014) \\
Density $\left(\rho_{\mathrm{i}}\right)$ & PC-SAFT (Gross and Sadowski, \\
Vapor pressure $\left(P_{i}^{s a t}\right)$ & PC-SAFT (Gross and Sadowski, \\
Open cup flash point $\left(T_{f i}\right)$ & 2001) \\
Lethal concentration $\left(\log L C 50_{i}\right)$ & (Hukkerikar et al., 2012a)
\end{tabular}

(Nielsen et al., 2001)

(Nielsen et al., 2001)

\begin{tabular}{ccc}
\hline Target mixture property & Model \\
\hline Higher Heating Value, $H H V$ & Linear mixing rule & Eq.1 \\
Density at $15{ }^{\circ} \mathrm{C}, \rho$ & Linear mixing rule & Eq.1 \\
Reid Vapor Pressure, $R V P$ & Modified Raoult's law & Eq.2 \\
Open cup flash point, $T_{f}$ & Liaw, Gerbaud, and Li (2011) & Eq.3 \\
Toxicity parameter, $-\log \left(L C_{50}\right)$ & Linear mixing rule & Eq.1 \\
ASTM distillation temperature & Hoffman (1969) & - \\
Research Octane number, $R O N$ & & \\
Dynamic viscosity at $20{ }^{\circ} \mathrm{C}, \eta$ & Linear mixing rule & Eq.1 \\
& Linear mixing rule (Cao et al., 2017; & Eq.1/Eq. $4-11$ \\
\hline
\end{tabular}

The linear mixing rule as shown in Eq. 1 is employed as the first estimate for mixture properties known to have a linear composition dependence: 


$$
\beta=\sum_{1}^{n} x_{i} \beta_{i}
$$

1

where, $x_{i}$ is the mole fraction of compound $i$ and $\beta_{i}$ is pure compound property of compound $i$. This model gives a good prediction for mixtures that have negligible excess properties of mixing (ideal mixtures). For non-ideal mixtures, the estimated properties need to be verified using rigorous models since their excess properties of mixing need to be considered.

RVP (Reid Vapor Pressure) of a blend is a function of mole fraction $\left(x_{i}\right)$, liquid activity coefficient $\left(\gamma_{i}\right)$ and saturated vapor pressure $\left(P_{i}\right)$ as shown in Eq. 2:

$$
R V P=\sum_{i=1}^{n} x_{i} \gamma_{i} P_{i}^{s a t}
$$

Flash point is defined as the lowest temperature at which the vapor above a liquid can be ignited in air. The flash point of a blend is determined using Eq. 3. It is the function of mole fraction $\left(x_{i}\right)$, liquid activity coefficient $\left(\gamma_{\mathrm{i}}\right)$, the saturated vapor pressure at temperature $\mathrm{T}\left(P_{i}^{s a t}\right)$ and the vapor pressure of pure compounds at their flash point $\left(P_{i, T_{f}}^{s a t}\right)$. Note that the liquid activity coefficient is predicted with the wellknown UNIFAC group contribution method with fine-tuned interaction parameters Kalakul et al. (2017)

$$
\sum_{i=1}^{n} \frac{x_{i} \gamma_{i} P_{i}^{s a t}(T)}{P_{i, T_{f}}^{s a t}}=1
$$

In this work, Linear mixing rule for density and viscosity calculations provides a good initial estimation for the blends. However, the rigorous viscosity model obtained from Cao et al. (1993) issued to correct the composition with the viscosity recalculated with the non-linear model as shown in Eq. 4 - 11:

$$
\begin{aligned}
\ln (\eta V)=\sum_{i}^{N C} \varphi_{i} \ln \left(\eta_{i} V_{i}\right) & +2 \sum_{i}^{N C} \varphi_{i} \ln \left(\frac{x_{i}}{\varphi_{i}}\right)-\sum_{i}^{N C}\left(\frac{q_{i} n p_{i} \varphi_{i}}{r_{i}}\right) \sum_{j}^{N C} \theta_{j i} \ln \left(\tau_{j i}\right) \\
\mathrm{V} & =\sum_{i}^{N C} x_{i} V_{k} \\
r_{i} & =\sum_{i}^{N C} v_{k, i} R_{k} \\
q_{i} & =\sum_{i}^{N C} v_{k, i} Q_{k} \\
\tau_{i j} & =\exp \left(-\frac{a_{m n}}{T}\right) \\
\varphi_{i} & =\frac{x_{i} r_{i}}{\sum_{j}^{N C} x_{j} r_{j}}
\end{aligned}
$$




$$
\theta_{j i}=\frac{\theta_{j} \tau_{j i}}{\sum_{l}^{N C} \theta_{l} \tau_{l i}}
$$

$$
\theta_{j}=\frac{x_{j} q_{j}}{\sum_{i}^{N C} x_{i} q_{i}}
$$

where $\eta$ is the mixture viscosity, $V$ is the mixture volume that can be calculated. $V_{i}\left(\mathrm{~cm}^{3} / \mathrm{mol}\right)$ and $\eta_{i}$ are pure compound molar volume and viscosity. $v_{k, i}, R_{k}$ and $Q_{k}$ are group parameters obtained from Magnussen et al. (1981). $\tau_{i j}$ is calculated from the group interaction parameters $a_{m n} . \varphi$ is volume fraction. $\theta_{j i}$ is parameter. $\theta_{j}$ is surface fraction.

\section{$3 \quad$ Verification by experimental techniques}

\subsection{Materials}

In this study, the chemicals used in preparation of five gasoline blends are $n$-butane, $n$-heptane, isooctane, 1-pentene, methylcyclopentane (MeCP), toluene, tetrahydrofuran (THF), 2-methyl tetrahydrofuran (MeTHF), acetone (ACE), 2-butanone (2BE) and ethanol (ETOH). All the chemicals are procured from Sigma-Aldrich and have a purity of $\geq 99 \%$. The blending procedure is carried out following the compositions provided in Table 2 and Table 3 in Section 2.

\subsection{Blend preparation and sampling technique}

For any gasoline grade, the octane number is fixed throughout the year, but $R V P$ varies according to the climate condition. In industry, butane is added to gasoline to improve the $R V P$ of the fuel and the concentration of butane is increased as the cooler weather sets in. Butane is an inexpensive gas and its presence in fuel can cause significant improvement in the $R V P$ of the fuel due to its higher vapor pressure of $244 \mathrm{kPa}$. A regular summer gasoline contains approximately 2\% butane (Pugliaresi, 2015). However, butane cannot be directly added to the storage tank, as the tank is not designed for the preparation of the gasoline-butane mixture. Industries use special techniques for the blending of butane on a large scale (Technics, 2012).

The gasoline blends formulated in this study have a high $n$-butane concentration (approximately $5 \%$ ). $\mathrm{N}$ Butane, having a very high vapor pressure of $244 \mathrm{kPa}$ at $25{ }^{\circ} \mathrm{C}$, has the tendency to escape on exposure to ambient conditions. Moreover, 1-pentene, which also has a high vapor pressure of $80.4 \mathrm{kPa}$ at $25^{\circ} \mathrm{C}$, is highly volatile in nature. Therefore, the blend composition is prone to change on its exposure to ambient conditions due to the escaping nature of both $n$-butane and 1-pentene. The conventional blending and sampling techniques, as well as testing methods, were found to be insufficient for the highly volatile mixtures used in this study. Therefore, to minimize changes in the composition of the gasoline blends, an advanced blending technique and a unique sampling methodology was developed. Figs. $1 \& 2$ shows the different stages of blend preparation technique and the sampling device used in this study. The detailed description of blend preparation technique and sampling protocol is provided in the supplementary documents. The techniques developed herein are paramount because it allowed us to prepare a blend with a composition comparable to the formulation predicted by the model. 


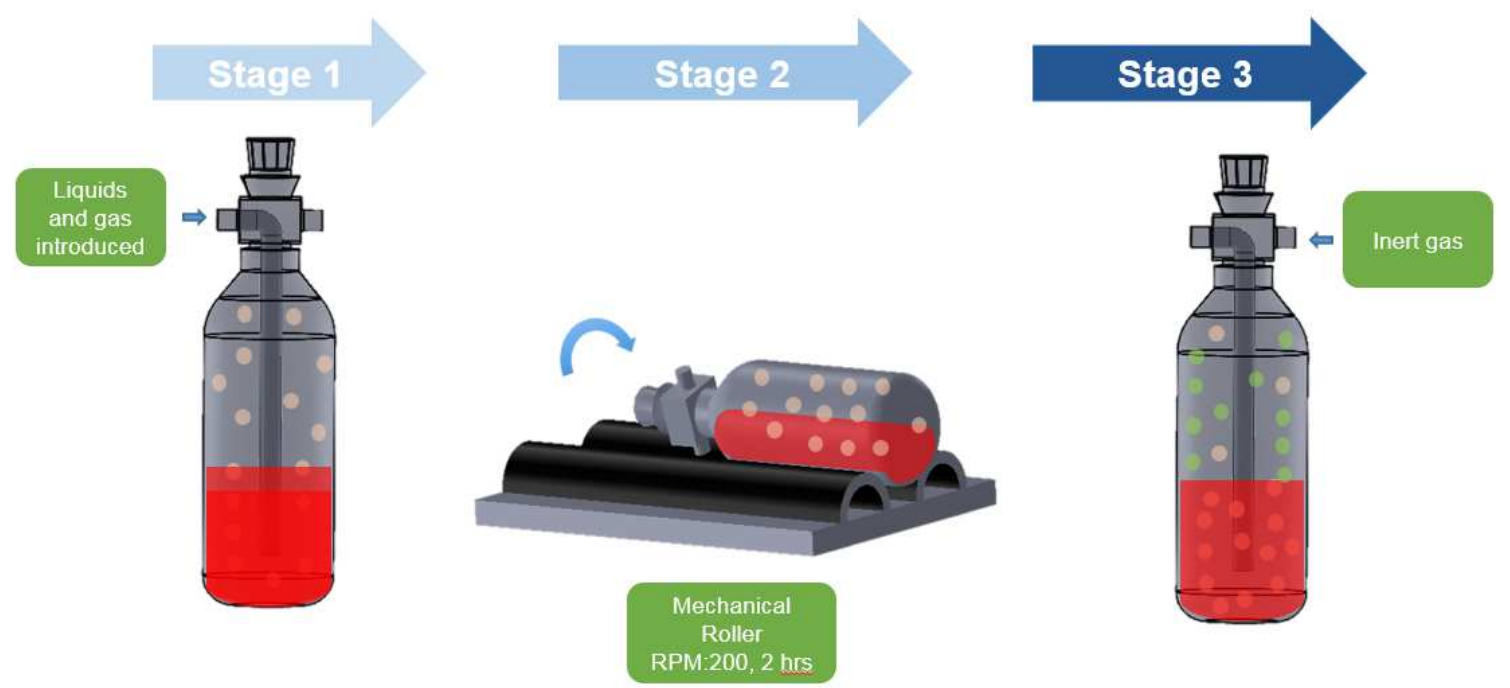

2

Figure 1: Blend Preparation

\begin{tabular}{ll}
\hline & Key \\
\hline Red color circles & Butane gas molecules \\
Red color & Gasoline mixture (liquids) \\
Green color circles & Helium gas molecules \\
\hline
\end{tabular}

3

4 
3

4

5

6

7

8

9

10

11

12

13

14

15

16

(1)

(1)

(1)

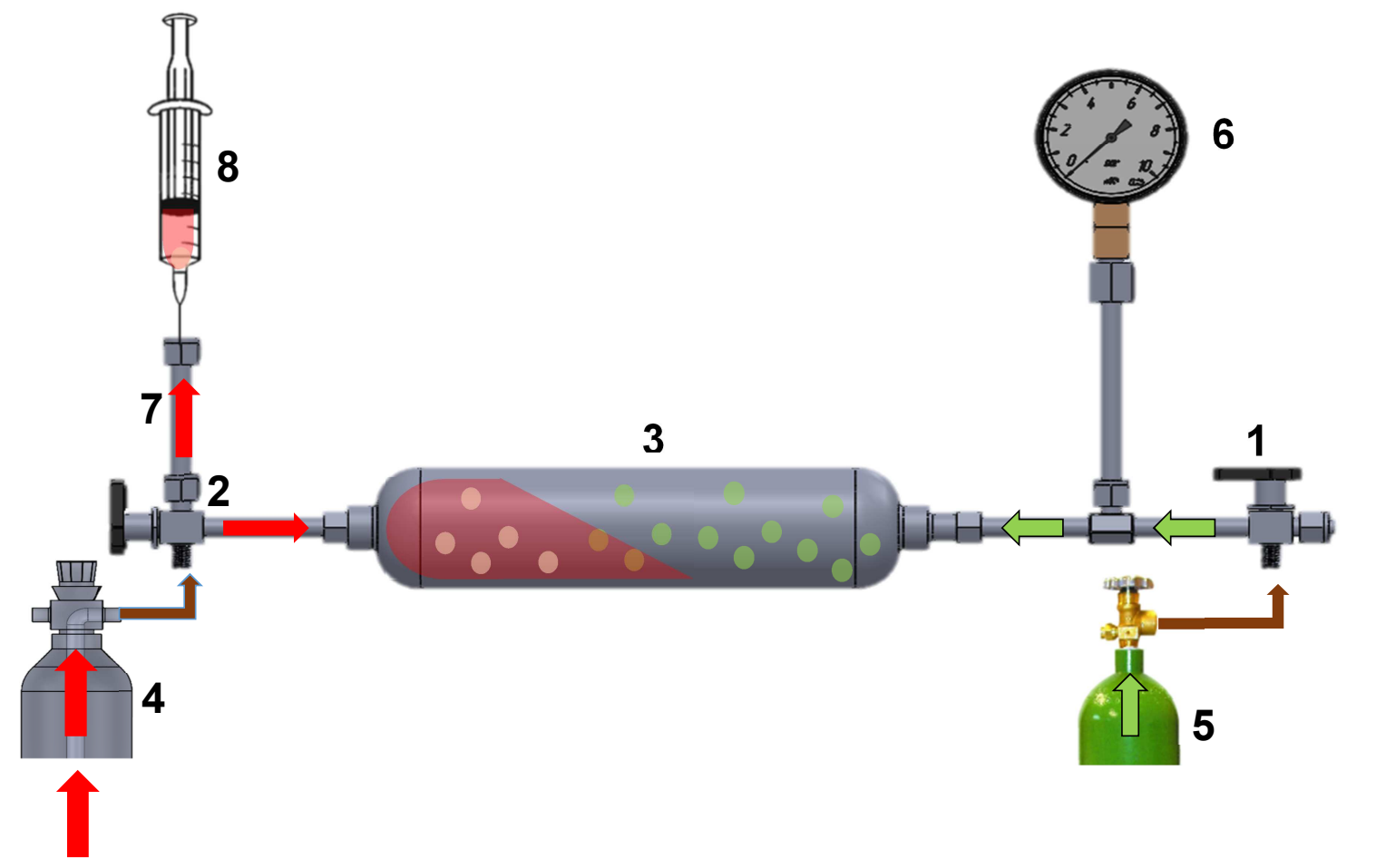

Figure. 2 : Sampling device: (1)TWV 1; (2)TWV 2; (3) $300 \mathrm{ml}$ double ended gas cylinder; (4) Sample injection; (5) Helium gas pressure applied; (6) Pressure gauge (PG); (7) SS316 tube of OD 1/4"; (8) Sample withdrawing in syringe

\subsection{Properties testing methods}

To experimentally test the gasoline blends, the following properties - Reid vapor pressure (RVP), density $(\rho)$, dynamic viscosity $(\eta)$, distillation temperatures $(\mathrm{T} 10, \mathrm{~T} 50, \mathrm{~T} 90)$, research octane number $(R O N)$ and composition characteristics - are measured using different equipment and standards. $R V P$ for the blends is determined using Equipment MiniVapXpert by the manufacturer Grabner Instruments according to ASTM D323. Density $(\rho)$ and dynamic viscosity $(\eta)$ for all the blends are measured using a Stabinger viscometer by Anton Paar according to ASTM 7042. Composition characteristics, distillation temperatures, and RON are measured by the Gas Chromatography-Detailed Hydrocarbon Analysis (GCDHA) technique using equipment Perkin-Elmer Clarus-500 according to ASTM D6730.

For GC-DHA technique, the sample is injected into a gas chromatograph which comprises of an open tubular (capillary) column coated with a methyl silicone liquid phase, modified with a capillary precolumn. The vaporized sample gets transported through the column by helium carrier gas. In the column, it gets partitioned into individual components, which after they elute from the end of the column, are detected by the flame ionization detector (FID). Analyzing reference standards or samples are used to identify each eluting component by comparison of their retention time under identical conditions. This 
process helps in determining the concentration of each component in wt \% after correction with detector response factors and normalization of the peak areas.

Usually, the boiling range characteristics through distillation are determined experimentally using ASTM D86. However, in this study the distillation curve is not determined using ASTM D86 for any of the blends due to safety concerns associated, owing to the presence of $n$-butane in the blends. Consequently, distillation temperatures are determined by GC-DHA technique for all the blends. The GC-DHA technique uses simulated distillation (SD) by a gas chromatography (GC) in which hydrocarbon components of the sample are eluted in order of increasing boiling points in a nonpolar capillary column (methyl silicone phase) as described elsewhere (Petroff et al., 1987). Petroff et al. (1987) compared the SD method for determining boiling temperatures with true boiling point (TBP) distillation via ASTM D86-78/ASTM D1160-77. Petroff et al. (1987) showed that the boiling point ranges derived from this SD technique are roughly comparable to TBP value, and therefore should only be used as an approximation of the distillation profile for the blends.

$R O N$ value is also experimentally determined by GC-DHA technique using the following relationship:

$$
R O N=\sum_{i=1}^{n}\left(a_{i} c_{i}\right)
$$

where, $c_{i}$ is the composition of component $i$ and $a_{i}$ is octane number of the compound $i$.

The octane number of each compound is already present in the in-built library supplied with the equipment, and the composition is determined by normalization of the peak areas after correction with detector response factor. Eq. 12 inevitably exhibits linear combination of the octane number and the composition of each compound. However, the octane number of the blend is not a linearly mixed property as interactions are present between the different chemicals (oxygenates, paraffins, aromatics, naphthenes and olefins) (Lugo et al. 1999). Therefore, RON values reported in this study needs further investigation through ASTM D2699.

Nevertheless, RON determination done using GC-DHA technique is an excellent method for approximation only. Octane number calculation using the linear mixing rule and ASTM method reported by Lugo et al. (1999) indicates a difference of \pm 2.8 RON.

$H H V$ is generally measured using ASTM D240 for liquid hydrocarbon fuels using a bomb calorimeter. In this study, $H H V$ is not measured owing to the highly volatile nature of the gasoline surrogate blends and determination of $H H V$ of the volatile blends creates a safety concern.

\section{$4 \quad$ Results and discussion}

\subsection{Composition analysis by GC DHA}

In this section, the concentration of each compound present in the blends as obtained by GC-DHA study according to ASTM D6730-01 is compared with the prepared blend concentration. Since the composition of all the blends is already known, the primary purpose of carrying out GC-DHA is to confirm that no alteration in composition occurs due to unknown chemical reaction or evaporation of volatile compounds like 1-Pentene and $n$-butane. Moreover, GC-DHA also helps in confirming the miscibility of the mixtures, which is a constraint, added in the computer-aided method. All the chromatograms and composition data 
1 from the GC-DHA analysis can be found in supplementary material provided with this paper (Fig. S1 -S6

2 \& Table S1-S6 ).

3 The variation of blended composition from the composition determined using GC-DHA technique is 4 presented in terms of Relative Standard Deviation (RSD) as shown in Table 6. RSD is a standardized 5 measure of variation in data that is given by the ratio of standard deviation $(\sigma)$ and the mean $(\mu)$. RSD is 6 expressed in percentage and can be calculated by Eq. 13:

$$
R S D=\sigma / \mu \times 100
$$

RSD values in Table 6 did not exceed $6.24 \%$ for any of the components in all the blends, which suggests that the prepared blend compositions did not change significantly from the predetermined composition. Moreover, the small RSD values also indicate that the fuel blend candidates are miscible. Relatively larger RSD values for 1-pentene and $n$-butane in comparison with other blend chemicals are observed due to the high volatility nature of 1 -pentene and $n$-butane, which renders subtle losses during sampling. Moreover, the blends are prepared with an accuracy of $\pm 2 \%$, and there is a possibility that this might have also contributed to the difference. The small deviations in results of blend compositions as denoted by their RSD values confirm the efficacy of the stability algorithm, blend preparation and sampling techniques used in this study. 
Table 6: Composition verification of all blends using DHA

\begin{tabular}{|c|c|c|c|c|c|c|c|c|c|c|c|c|c|c|c|c|c|c|}
\hline & \multicolumn{3}{|c|}{ MI } & \multicolumn{3}{|c|}{ Blend 1} & \multicolumn{3}{|c|}{ Blend2 } & \multicolumn{3}{|c|}{ Blend3 } & \multicolumn{3}{|c|}{ Blend4 } & \multicolumn{3}{|c|}{ Blend5 } \\
\hline & $\begin{array}{c}\mathbf{X} \\
(w t \%)\end{array}$ & $\begin{array}{c}\mathbf{Y} \\
(\mathbf{w t} \%)\end{array}$ & $\begin{array}{l}\text { RSD } \\
(\%)\end{array}$ & $\begin{array}{c}\mathrm{X} \\
(\mathrm{wt} \%)\end{array}$ & $\begin{array}{c}\mathbf{Y} \\
(\mathbf{w t} \%)\end{array}$ & $\begin{array}{l}\text { RSD } \\
(\%)\end{array}$ & $\begin{array}{c}\mathbf{X} \\
(\mathbf{w t} \%)\end{array}$ & $\begin{array}{c}\mathbf{Y} \\
(\mathbf{w t} \%)\end{array}$ & $\begin{array}{l}\text { RSD } \\
(\%)\end{array}$ & $\begin{array}{c}X \\
(w t \%)\end{array}$ & $\begin{array}{c}\mathrm{Y} \\
(\mathrm{wt} \%)\end{array}$ & $\begin{array}{c}\text { RSD } \\
(\%)\end{array}$ & $\begin{array}{c}\mathrm{X} \\
\text { (wtl\% } \\
\text { ) }\end{array}$ & $\begin{array}{c}\mathbf{Y} \\
(\mathbf{w t} \%)\end{array}$ & $\begin{array}{l}\text { RSD } \\
(\%)\end{array}$ & $\begin{array}{c}\mathrm{X} \\
(\mathbf{w t} \%)\end{array}$ & $\begin{array}{c}Y \\
(w t \%)\end{array}$ & $\begin{array}{l}\text { RSD } \\
(\%)\end{array}$ \\
\hline n-butane & 6.58 & 6.06 & 5.82 & 4.24 & 3.94 & 5.19 & 4.17 & 4.00 & 2.94 & 4.57 & 4.26 & 4.96 & 4.73 & 4.33 & 6.24 & 4.89 & 4.48 & 6.19 \\
\hline 1-pentene & 3.63 & 3.46 & 3.39 & 2.34 & 2.24 & 3.09 & 2.30 & 2.20 & 3.14 & 2.52 & 2.41 & 3.16 & 2.61 & 2.44 & 4.76 & 2.70 & 2.53 & 4.60 \\
\hline Methylcyclopentane & 8.47 & 8.31 & 1.35 & 5.46 & 5.34 & 1.57 & 5.37 & 5.24 & 1.73 & 5.88 & 5.77 & 1.34 & 6.09 & 5.90 & 2.24 & 6.29 & 6.08 & 2.40 \\
\hline Iso-octane & 53.99 & 54.33 & 0.44 & 34.81 & 34.82 & 0.02 & 34.21 & 34.07 & 0.29 & 37.48 & 38.09 & 1.14 & 38.81 & 38.96 & 0.27 & 40.09 & 39.67 & 0.74 \\
\hline n-heptane & 12.60 & 12.85 & 1.39 & 8.12 & 8.24 & 1.04 & 7.98 & 8.06 & 0.71 & 8.75 & 9.01 & 2.07 & 9.05 & 9.23 & 1.39 & 9.36 & 9.41 & 0.38 \\
\hline Toluene & 14.73 & 14.97 & 1.14 & 9.50 & 9.59 & 0.67 & 9.33 & 9.38 & 0.38 & 10.23 & 10.59 & 2.45 & 10.59 & 10.82 & 1.52 & 10.94 & 11.00 & 0.39 \\
\hline Tetrahydrofuran (THF) & - & - & - & 12.94 & 12.08 & 4.86 & - & & - & - & - & - & - & - & - & - & - & - \\
\hline $2-$ & - & - & - & 22.60 & 23.77 & 3.57 & 22.87 & 24.07 & 3.62 & - & - & - & 13.91 & 14.40 & 2.45 & 12.83 & 13.39 & 3.02 \\
\hline $\begin{array}{c}\text { Methyltetrahydrofuran } \\
\text { Acetone }\end{array}$ & - & - & - & - & - & - & 13.77 & 12.97 & 4.23 & 10.80 & 10.22 & 3.90 & - & - & - & - & - & - \\
\hline 2-Butanone & - & - & - & - & - & - & & - & - & 19.78 & 19.65 & 0.47 & 14.20 & 13.92 & 1.41 & - & - & - \\
\hline Ethanol & - & - & - & - & - & & - & - & - & - & - & - & - & - & - & 12.93 & 13.44 & 2.74 \\
\hline
\end{tabular}

Where:

$\mathrm{X}=$ Blend Composition (wt \%)

$\mathrm{Y}=$ DHA Composition (wt \%) 


\subsection{Results of model prediction vs. experimental data}

The properties of the prepared surrogate fuels obtained from Yunus et al. (2014) are re-calculated using the property models in VPPD-Lab. Results obtained from Yunus et al. (2014), and extended calculations through rigorous property models in VPPD-Lab are compared with the experimental results and the variation for both model-simulated results [Yunus et al. (2014) and VPPD-Lab] with the experimental results presented in terms of RSD values. The model-simulated results in comparison with the experimental data of $R V P, \rho, \eta, R O N$ and distillation temperatures (T10, T50 and T90) are given in Table 7, Table 8 , Table 9 , Table 10 and Table 11 respectively.

The RVP values predicted by the Yunus et al. (2014) model are found to be lower for blends 2-5 and higher for MI as compared to results obtained from the experiment. Only for blend 1, the model predictions by Yunus et al. (2014) is in good agreement with the experimental results. Assuming ideal solution behavior, activity coefficients for all the molecules present in the blends are considered to be unity for the sake of simplicity of calculations. This assumption inevitably means that there is a negligible interaction between the molecules of the different compounds in blends. However, results given in Table 7 suggest that this hypothesis is not consistent. To improve the model prediction on $R V P$, interactions between the molecules are considered in the VPPD-Lab model, which accounts for the non-ideality of the mixture and requires the incorporation of the activity coefficient of all the compounds. Results of $R V P$ values and their RSD values are given in Table 7 which reflect an improvement in the model prediction of $R V P$.

The experimental values of $\rho$ are in close agreement with the model prediction which can be observed from their RSD values given in Table 8. Similarly, both Yunus et al. (2014) model results and VPPDLab results for $\eta$ are also in good agreement with the experimental data as shown in Table 9. The application of the more rigorous models for viscosity in VPPD-Lab (Eq. 4 - Eq. 11) helps in improving the results of viscosity for all blends as evident from the lower RSD values. Both models can be used to calculate the viscosity of the surrogates with a considerable accuracy as evident from the low RSD values.

The RON values obtained using GC-DHA for MI and blend 5 are slightly lower than the Yunus et al. (2014) model calculation for RON as given in Table 10. The difference in results can be attributed to the slight change in composition that occurs while injecting the sample in the GC.

The distillation temperatures (T10, T50 and T90), given in Table 11, calculated in VPPD-Lab are in excellent agreement with the GC-DHA results of distillation temperatures as indicated by the very low RSD values. The exceptions are T10 of Blend 2 and Blend 3, where slightly higher RSD values of $9.98 \%$ and $10.19 \%$ are reported respectively. Nonetheless, the agreement of the model and experimental results indicates that it can be added as a constraint to the model which will help improve screening of the right candidates for fuel blends.

It is worth noting here that experimental data is used to confirm the credibility of Yunus et al. (2014) model and to identify its shortcomings. As for the case of $R V P$ of gasoline blends, experimental data was found to be much higher than the predicted values. Similarly, the model prediction of $\eta$ of the gasoline blends requires improvement as the predicted values slightly deviate from the experimentally measured ones. Thus fine tuning of these properties is necessary to improve the model capabilities. This was accomplished by integrating either non-ideality of the mixture or non-linearity of physicochemical properties as given in Eq. 2 or Eq. 4. Thus an experimental feedback helped to converge the model predictions and currently used to measure a wider range of properties. 
Table 7: Comparison of experimentally determined RVP value of gasoline surrogate blends with their predicted values using 3 different computational model

\begin{tabular}{c|ccc|c|c}
\hline \multirow{2}{*}{ ID } & \multicolumn{3}{|c|}{ RVP $(\boldsymbol{k P a})$} & & \\
\cline { 2 - 6 } & Experimental & $\begin{array}{c}\text { Model } \\
\text { (Yunus et al. 2014) }\end{array}$ & $\begin{array}{c}\text { Model } \\
\text { (VPPD-Lab) }\end{array}$ & $\begin{array}{c}\text { RSD (\%) } \\
\text { (Yunus et al. 2014) }\end{array}$ & $\begin{array}{c}\text { RSD (\%) } \\
\text { (VPPD-Lab) }\end{array}$ \\
\hline MI & 51.0 & 55.2 & 54.0 & 5.54 & 4.04 \\
Blend 1 & 46.2 & 46.0 & 50.8 & 0.31 & 6.71 \\
Blend 2 & 60.4 & 46.0 & 64.5 & 19.14 & 4.64 \\
Blend 3 & 58.9 & 49.0 & 63.7 & 12.98 & 5.54 \\
Blend 4 & 50.1 & 45.0 & 53.5 & 7.58 & 4.64 \\
Blend 5 & 55.1 & 45.0 & 58.9 & 14.27 & 4.71 \\
\hline
\end{tabular}

4

5

Table 8: Density ( $\rho$ ) of gasoline surrogate blends comparison with experimental value

\begin{tabular}{c|cc|c}
\hline \multirow{2}{*}{ ID } & \multicolumn{2}{|c|}{$\begin{array}{c}\text { at } \mathbf{~ 1 5}^{\mathbf{0}} \mathbf{C} \\
\left(\frac{\mathbf{g}}{\mathbf{c m}^{\mathbf{3}}}\right)\end{array}$} & \multicolumn{2}{c}{} \\
& Experimental & $\begin{array}{c}\text { Model } \\
\text { (VPPD-Lab) }\end{array}$ & RSD (\%) \\
\cline { 2 - 4 } & & 0.7260 & 1.45 \\
MI & 0.7113 & 0.7709 & 1.04 \\
Blend 1 & 0.7596 & 0.7618 & 1.27 \\
Blend 2 & 0.7482 & 0.7480 & 1.40 \\
Blend 3 & 0.7333 & 0.7528 & 1.26 \\
Blend 5 & 0.7395 & 0.7487 & 1.24 \\
\hline
\end{tabular}

6 


\section{ACCEPTED MANUSCRIPT}

Table 9: Comparison of viscosity ( $\eta$ ) of gasoline surrogate blends with experimental value

\begin{tabular}{c|ccc|c|c}
\hline \multirow{2}{*}{ ID } & \multicolumn{3}{|c|}{$\eta$ at 20 $\mathbf{0}^{\mathbf{C} \text { (mPa.s) }}$} & \\
\cline { 2 - 6 } & Experimental & $\begin{array}{c}\text { Model } \\
\text { (Yunus et al. 2014) }\end{array}$ & $\begin{array}{c}\text { Model } \\
\text { (VPPD-Lab) }\end{array}$ & $\begin{array}{c}\text { RSD (\%) } \\
\text { (Yunus et al. 2014) }\end{array}$ & $\begin{array}{c}\text { RSD (\%) } \\
\text { (VPPD-Lab) }\end{array}$ \\
\hline MI & 0.50 & 0.51 & 0.51 & 1.40 & 1.40 \\
Blend 1 & 0.54 & 0.48 & 0.54 & 8.32 & 0 \\
Blend 2 & 0.46 & 0.47 & 0.45 & 1.52 & 1.55 \\
Blend 3 & 0.45 & 0.48 & 0.43 & 4.56 & 3.21 \\
Blend 4 & 0.46 & 0.50 & 0.46 & 5.89 & 0 \\
Blend 5 & 0.61 & 0.57 & 0.62 & 4.79 & 1.15 \\
\hline
\end{tabular}

2

Table 10: Comparisons of RON of gasoline fuel surrogates with GC-DHA technique used

\begin{tabular}{cccccc}
\hline ID & \multicolumn{3}{c}{ RON } & & \\
& GC-DHA & $\begin{array}{c}\text { Model } \\
\text { (Yunus et al. 2014) }\end{array}$ & $\begin{array}{c}\text { Model } \\
\text { VPPD-Lab }\end{array}$ & $\begin{array}{c}\text { RSD (\%) } \\
\text { (Yunus et al. }\end{array}$ & $\begin{array}{c}\text { RSD (\%) } \\
\text { VPPD-LAB }\end{array}$ \\
\hline MI & 91 & 92 & 92 & $0.77)$ & 0.77 \\
Blend 1 & 88 & - & - & - & - \\
Blend 2 & 91 & - & - & - & - \\
Blend 3 & 98 & - & - & - & - \\
Blend 4 & 93 & - & 96 & 0.74 & 0.74 \\
Blend 5 & 95 & 96 & & & \\
\hline
\end{tabular}

4

5

6

Table 11: Distillation temperatures (T10, T50 and T90) of gasoline fuel surrogates

\begin{tabular}{|c|c|c|c|c|c|c|c|c|c|}
\hline \multirow{2}{*}{ ID } & \multicolumn{2}{|c|}{$\mathrm{T} 10\left({ }^{\circ} \mathrm{C}\right)$} & \multirow{2}{*}{ RSD (\%) } & \multicolumn{2}{|c|}{ T50 $\left({ }^{\circ} \mathrm{C}\right)$} & \multirow{2}{*}{$\begin{array}{l}\text { RSD } \\
(\%)\end{array}$} & \multicolumn{2}{|c|}{$\mathrm{T} 90\left({ }^{\circ} \mathrm{C}\right)$} & \multirow{2}{*}{$\begin{array}{l}\text { RSD } \\
(\%)\end{array}$} \\
\hline & Exp. & $\begin{array}{c}\text { Model } \\
\text { (VPPD-Lab) }\end{array}$ & & Exp. & $\begin{array}{c}\text { Model } \\
\text { (VPPD-Lab) }\end{array}$ & & Exp. & $\begin{array}{c}\text { Model } \\
\text { (VPPD-Lab) }\end{array}$ & \\
\hline MI & 72.0 & 72.0 & 0 & 99.0 & 99.0 & 0 & 111 & 109.3 & 1.09 \\
\hline Blend 1 & 66.0 & 70.7 & 4.86 & 98.0 & 98.4 & 0.29 & 99 & 103.2 & 2.94 \\
\hline Blend 2 & 56.0 & 64.5 & 9.98 & 98.0 & 98.1 & 0.07 & 99 & 103.2 & 2.94 \\
\hline Blend 3 & 56.0 & 64.7 & 10.19 & 98.0 & 98.6 & 0.43 & 99 & 100 & 0.71 \\
\hline Blend 4 & 72.0 & 73.6 & 1.55 & 99.0 & 99.0 & 0 & 99 & 100 & 0.71 \\
\hline Blend 5 & 72.0 & 73.0 & 0.98 & 99.0 & 99.0 & 0 & 99 & 97 & 1.44 \\
\hline
\end{tabular}




\section{Conclusion}

The gasoline blends formulated though the fine-tuned model-based method of Yunus et al. (2014) has been extended to: firstly to re-calculate the target physical properties, such as $\rho, \eta$ and $R V P$, and then to improve these predictions with new extended models; and secondly to add more property constraints such as $T_{f}$ and distillation temperatures. The calculations of the surrogate fuel properties are extended through rigorous models implemented in VPPD-Lab that provide a way for the surrogate candidates to go through additional screening in terms of a wider range of properties.

In the first stage of our experimental campaign, a sophisticated sampling methodology was developed to ensure minimal composition variation during the analysis. The effectiveness of the blending and sampling methodologies have been verified using GC-DHA. Smaller RSD values for the composition of the blends confirm not only the efficacy of the blending and sampling techniques employed in this study but also the stability algorithm used in the screening of the blends to ensure miscibility of the blend compounds.

The results of modeling the physicochemical properties with the extended models are found to be in solid agreement with the experimental results. Moreover, the extended calculations of $\eta, \rho$ and distillation temperatures are also found to be in good agreement with the experimental results for all gasoline blends. The surrogate fuels developed through the extended calculations can further be used in the studies that numerically simulate the combustion behavior of the fuel, simiar to the concept used in our diesl fuel surrogate work (Choudhury et al., 2017). A simulation of combustion will help in designing a better gasoline fuel which can be used in existing engines without the typical compromises of power and efficiency that are significant challenges for fuels coming from the synthetic route. Additionally, butane used in the MI should be substituted with compounds that are highly soluble in other liquid hydrocarbons present in the blend. Such a surrogate or gasoline blend will be more realistic since the composition would not vary significantly with climate conditions as that of the case for butane blends.

This approach can, therefore, complement the regression-based studies found in literature as it involves a more mechanistic approach toward development of a tailor-made composition. It is intended as an additional tool to design synthetic fuels by optimizing the blends concerning multiple properties by setting the appropriate property bounds and considering a much wider range of chemicals. The present study details a model-based system using collected state-of-the-art property models which helps generate reliable gasoline surrogate blends efficiently. The approach pursued herein provides attractive candidates that can be further tested and verified experimentally. A similar approach has been implemented to design new generations of diesel fuel surrogates that mimic Gasto-Liquid (GTL) diesel fuel (Choudhury et al., 2017). This procedure reduces the time needed to develop the product while simultaneously avoiding trial-and-error approaches. Finally, because of the predictive nature of the model, it is possible to obtain new and innovative fuels from either conventional crude oil sources or non-conventional sources (e.g. from natural gas, via GTL, coal, via Coal-to-Liquid (CTL), or biofuels).

\section{Acknowledgements}

This work was supported by NPRP award [NPRP 5-066-2-023] from the Qatar National Research Fund, which is a member of the Qatar Foundation. The statements made herein are solely the responsibility of the authors. 


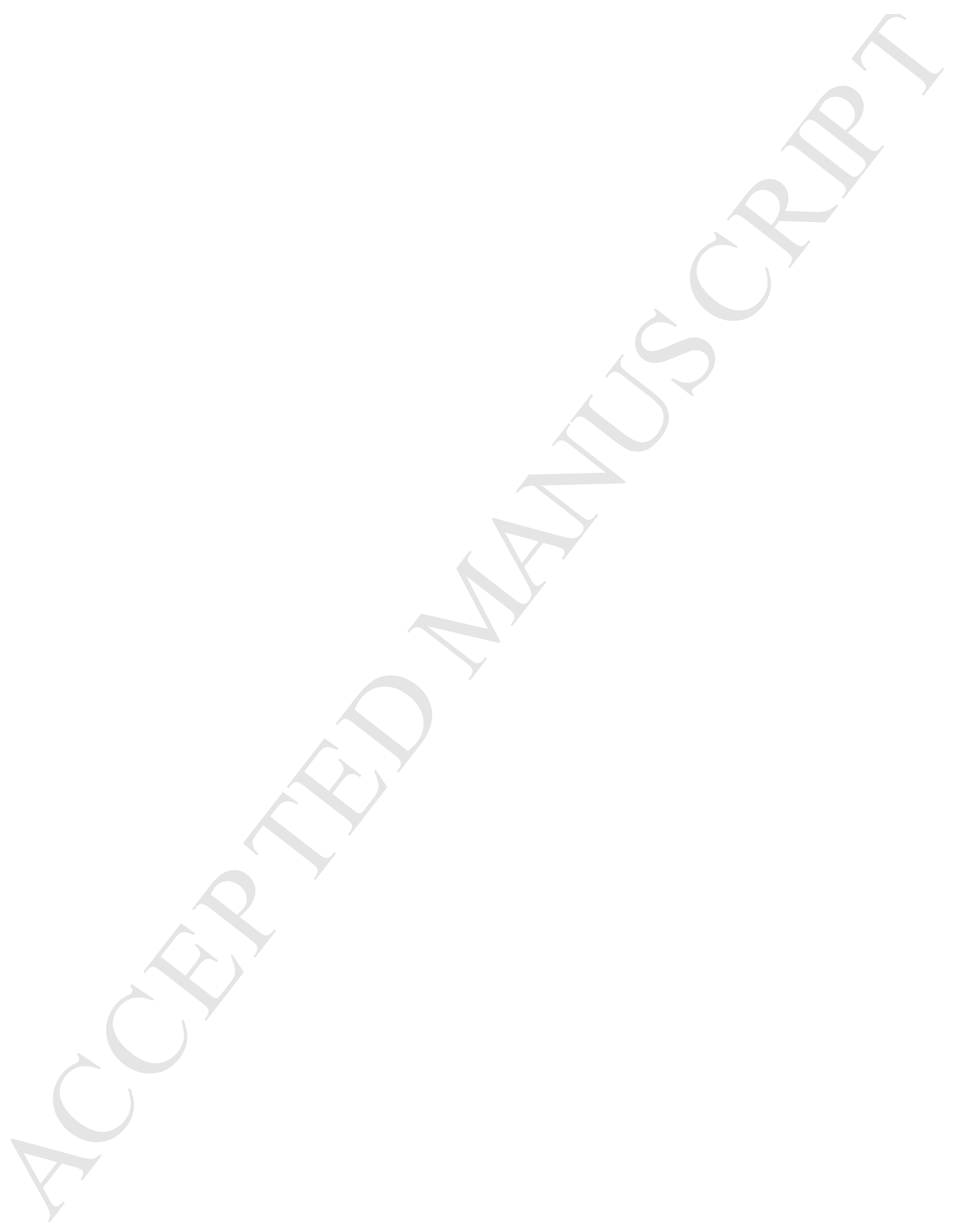




\section{Supporting information}

2 Blend preparation and sampling technique are provided. Additionally, the chromatogram for all the

3 blends and their compositions determined through GC-DHA are given in Fig S1-Fig S6 and Table S1-

4 Table S6.

\section{Notes}

6 The authors declare no competing financial interest.

\section{References}

Technics, An Introduction to Technics Butane Blenders Adjusting gasoline vapor pressure for your regional climate can enhance the profitability of your terminal and pipeline operations, n.d. http://www.technicsglobal.com/PDFs/TechnicsButaneBrochure.pdf. (accessed 10.10.. 2015).

Asher, W.E., Pankow, J.F., 2006. Vapor pressure prediction for alkenoic and aromatic organic compounds by a UNIFAC-based group contribution method. Atmos. Environ. 40, 3588-3600. doi:10.1016/j.atmosenv.2005.12.004

Canakci, M., Ozsezen, A.N., Alptekin, E., Eyidogan, M., 2013. Impact of alcohol-gasoline fuel blends on the exhaust emission of an SI engine. Renew. Energy 52, 111-117. doi:http://dx.doi.org/10.1016/j.renene.2012.09.062

Cao, W., Fredenslund, A., Rasmussen, P., 2017. Simultaneous Correlation of Viscosity and VaporLiquid Equilibrium Data. Ind. Eng. Chem. Res. 32, 2077-2087. doi: 10.1021/ie00021a033

Choudhury, H.A., Intikhab, S., Kalakul, S., Khan, M., Tafreshi, R., Gani, R., Elbashir, N.O., 2017. Designing a Surrogate Fuel for Gas-to-Liquid (GTL) Derived Diesel. Article under review.

Conte, E., Gani, R., Malik, T.I., 2011. The virtual Product-Process Design laboratory to manage the complexity in the verification of formulated products. Fluid Phase Equilib. 302, 294-304. doi:http://dx.doi.org/10.1016/j.fluid.2010.09.031

Elmalik, E.E., Raza, B., Warrag, S., Ramadhan, H., Alborzi, E., Elbashir, N.O., 2014. Role of Hydrocarbon Building Blocks on Gas-to-Liquid Derived Synthetic Jet Fuel Characteristics. Ind. Eng. Chem. Res. 53, 1856-1865. doi:10.1021/ie402486c

Gani, R., 2004. Chemical product design: challenges and opportunities. Comput. Chem. Eng. 28, 2441-2457. doi:http://dx.doi.org/10.1016/j.compchemeng.2004.08.010

Gross, J., Sadowski, G., 2001. Perturbed-Chain SAFT: An Equation of State Based on a Perturbation Theory for Chain Molecules. Ind. Eng. Chem. Res. 40, 1244-1260. doi:10.1021/ie0003887

Hoffman, E.J., 1969. Relations between true boiling point and ASTM distillation curves. Chem. Eng. Sci. 24, 113-117. doi:http://dx.doi.org/10.1016/0009-2509(69)80013-8

Hukkerikar, A.S., Kalakul, S., Sarup, B., Young, D.M., Sin, G., Gani, R., 2012a. Estimation of Environment-Related Properties of Chemicals for Design of Sustainable Processes: Development of Group-Contribution+ (GC+) Property Models and Uncertainty Analysis. J. Chem. Inf. Model. 52, 2823-2839. doi:10.1021/ci300350r

Hukkerikar, A.S., Sarup, B., Ten Kate, A., Abildskov, J., Sin, G., Gani, R., 2012b. Groupcontribution $+(\mathrm{GC}+)$ based estimation of properties of pure components: Improved property estimation and uncertainty analysis. Fluid Phase Equilib. 321, 25-43. doi:http://dx.doi.org/10.1016/j.fluid.2012.02.010 
Kalakul, S., Cignitti, S., Zhang, L., Gani, R., 2017. Chapter 3 - VPPD-Lab: The Chemical Product Simulator, in: Mariano Martín, M.R.E. and N.G.C.B.T.-C.A.C.E. (Ed.), Tools For Chemical Product DesignFrom Consumer Products to Biomedicine. Elsevier, pp. 61-94. doi:https://doi.org/10.1016/B978-0-444-63683-6.00003-4

Kalakul, S., Hussain, R., Elbashir, N., Gani, R., 2015. VPPD Lab -The Chemical Product Simulator, in: Krist V. Gernaey, J.K.H. and R.G.B.T.-C.A.C.E. (Ed.), 12th International Symposium on Process Systems Engineering and 25th European Symposium on Computer Aided Process Engineering. Elsevier, pp. 1415-1420. doi:http://dx.doi.org/10.1016/B978-0-444-635778.50081-4

Liaw, H.-J., Gerbaud, V., Li, Y.-H., 2011. Prediction of miscible mixtures flash-point from UNIFAC group contribution methods. Fluid Phase Equilib. 300, 70-82. doi:http://dx.doi.org/10.1016/j.fluid.2010.10.007

Lugo, H.J., Ragone, G., Zambrano, J., 1999. Correlations between Octane Numbers and Catalytic Cracking Naphtha Composition. Ind. Eng. Chem. Res. 38, 2171-2176. doi:10.1021/ie980273r

Luning Prak, D.J., Jones, M.H., Trulove, P., McDaniel, A.M., Dickerson, T., Cowart, J.S., 2015. Physical and chemical analysis of alcohol-to-jet (ATJ) fuel and development of surrogate fuel mixtures. Energy and Fuels 29, 3760-3769. doi:10.1021/acs.energyfuels.5b00668

Magnussen, T., Rasmussen, P., Fredenslund, A.,1981. UNIFAC Parameter Table for Prediction of Liquid-Liquid Equilibria. Ind. Eng.Chem. Process Des. Dev. 20, 331-339. doi: $10.1021 / \mathrm{i} 200013 \mathrm{a} 024$

Masum, B.M., Masjuki, H.H., Kalam, M.A., Palash, S.M., Habibullah, M., 2015. Effect of alcoholgasoline blends optimization on fuel properties, performance and emissions of a SI engine. J. Clean. Prod. 86, 230-237. doi:http://dx.doi.org/10.1016/j.jclepro.2014.08.032

Mehl, M., Chen, J.Y., Pitz, W.J., Sarathy, S.M., Westbrook, C.K., 2011. An Approach for Formulating Surrogates for Gasoline with Application toward a Reduced Surrogate Mechanism for CFD Engine Modeling. Energy \& Fuels 25, 5215-5223. doi:10.1021/ef201099y

Mueller, C.J., Cannella, W.J., Bruno, T.J., Bunting, B., Dettman, H.D., Franz, J.A., Huber, M.L., Natarajan, M., Pitz, W.J., Ratcliff, M.A., Wright, K., 2012. Methodology for Formulating Diesel Surrogate Fuels with Accurate Compositional, Ignition-Quality, and Volatility Characteristics. Energy \& Fuels 26, 3284-3303. doi:10.1021/ef300303e

Nielsen, T.L., Abildskov, J., Harper, P.M., Papaeconomou, I., Gani, R., 2001. The CAPEC Database. J. Chem. Eng. Data 46, 1041-1044. doi:10.1021/je000244z

Petroff, N., Hoscheitt, A., Durand, J.P., 1987. 16TH INTERNATIONAL SYMPOSIUM ON CHROMATOGRAPHYAutomated simulated distillation by gas chromatography . J. Chromatogr. A 395, 241-254. doi:http://dx.doi.org/10.1016/S0021-9673(01)94114-7

Pitz, W.J., Mueller, C.J., 2011. Recent progress in the development of diesel surrogate fuels. Prog. Energy Combust. Sci. 37, 330-350. doi:http://dx.doi.org/10.1016/j.pecs.2010.06.004

Pitz W J, Cernansky N P, Dryer F L, Egolfopoulos, Farrell J T, Friend D G, P.H., 2007. Development of an Experimental Database and Chemical Kinetic Models for Surrogate Gasoline Fuels. SAE $1,1-21$.

Pugliaresi, L., 2015. Gasoline Blending: An EPRINC Primer. (Homepage: http:// www.eprinc.org) accessed December 2015.

Reiter, A.M., Wallek, T., Pfennig, A., Zeymer, M., 2015. Surrogate Generation and Evaluation for Diesel Fuel. Energy \& Fuels 29, 4181-4192. doi:10.1021/acs.energyfuels.5b00422

Rodríguez-Antón, L.M., Gutiérrez-Martín, F., Martinez-Arevalo, C., 2015. Experimental 
determination of some physical properties of gasoline, ethanol and ETBE ternary blends. Fuel 156, 81-86. doi:http://dx.doi.org/10.1016/j.fuel.2015.04.040

3 Yunus, N.A., Gernaey, K. V, Woodley, J.M., Gani, R., 2014. A systematic methodology for design of tailor-made blended products. Comput. Chem. Eng. 66, 201-213.

6 doi:http://dx.doi.org/10.1016/j.compchemeng.2013.12.011 


\section{Appendix: Property Models Used}

\begin{tabular}{|c|c|c|c|}
\hline Pure component property & Model & Parameter & Remark \\
\hline $\begin{array}{l}\text { 1. Higher heating value (HHV) } \\
\text { 2. Measure of toxicity } \\
\text { (-LogLC50) }\end{array}$ & $\begin{aligned} f(X)=\sum_{i}^{N G 1} N_{i} C_{i p}+w & \sum_{i}^{N G 2} M_{j} D_{j p} \\
& +z \sum_{i}^{N G 3} O_{k} E_{k p}\end{aligned}$ & $\begin{array}{l}C_{i p} \text { is the contribution for the first- } \\
\text { order group of type } i \text { for property } \\
p \text { with } N_{i} \text { occurrences; } D_{j p} \text { is the } \\
\text { contribution for the second-order } \\
\text { group of type } j \text { for property } p \text { with } \\
M_{j} \text { and } E_{k p} \text { is the contribution of } \\
\text { the third-order group of type } k \text { for } \\
\text { property } p \text { with } O_{k} \text { occurrences; } \\
\text { and } w \text { and } z \text { are the constants for } \\
\text { the second-order and third-order } \\
\text { groups, respectively }\end{array}$ & Group contribution method \\
\hline \multirow[t]{2}{*}{ Liquid density } & $\begin{array}{l}\text { Zra }=0.29056-0.08775 \omega \\
\text { Temp }=1+\left(1-\frac{\mathrm{T}}{T c}\right)^{0.285714} \\
\rho=\left(83.14 \mathrm{Tc} \cdot \mathrm{Zra} a^{T e m p}\right) / P c\end{array}$ & $\begin{array}{l}\rho\left(\mathrm{g} / \mathrm{cm}^{3}\right) \text { is liquid density; } T c(\mathrm{~K}) \\
\text { is critical temperature, } P c(\mathrm{bar}) \text { is } \\
\text { critical pressure; } \omega \text { is Pitzer's } \\
\text { Acentric Factor; and T is } \\
\text { temperature }(\mathrm{K}) \text {. }\end{array}$ & Modified Rackett correlation \\
\hline & $\begin{array}{l}\text { PCSAFT equation of state (Gross and } \\
\text { Sadowski, 2001). }\end{array}$ & $\begin{array}{l}\text { The input parameters for the } \\
\text { calculation are: } \mathrm{Mw} \text { (molecular } \\
\text { weight, } \mathrm{g} / \mathrm{mol} \text { ); } \mathrm{m} \text { (segment } \\
\text { number); } \sigma \text { (segment diameter, } \AA \text { ); } \\
\varepsilon / k \text { is segment energy parameter } \\
(\mathrm{K}) \text {; and } \mathrm{T}(\mathrm{K}) \text { is temperature. }\end{array}$ & $\begin{array}{l}\text { Pressure-volume-temperature } \\
\text { relationship used to estimate } \\
\text { molar volume given pressure } \\
\text { and temperature }\end{array}$ \\
\hline \multirow[t]{2}{*}{ Vapor pressure } & $\begin{array}{l}\text { Modified SRK equation of state (SRK } \\
\text { EOS). }\end{array}$ & $\begin{array}{l}\text { The input parameters for Modified } \\
\text { SRK are: critical temperature, } \\
\text { critical pressure, acentiric factor }\end{array}$ & $\begin{array}{l}\text { Pressure-volume-temperature } \\
\text { relationship used to estimate } \\
\text { pressure given volume and } \\
\text { temperature }\end{array}$ \\
\hline & $\begin{array}{l}\text { PCSAFT equation of state (Gross and } \\
\text { Sadowski, 2001) }\end{array}$ & $\begin{array}{l}\text { The input parameters for PCSAFT } \\
\text { calculation are: } \mathrm{Mw} \text { (molecular } \\
\text { weight, } \mathrm{g} / \mathrm{mol}) ; \mathrm{m} \mathrm{(segment} \\
\text { number); } \sigma \text { (segment diameter, } \AA \text { ); } \\
\varepsilon / k \text { is segment energy parameter } \\
(\mathrm{K}) \text {; and } \mathrm{T}(\mathrm{K}) \text { is temperature. }\end{array}$ & $\begin{array}{l}\text { Pressure-volume-temperature } \\
\text { relationship used to estimate } \\
\text { pressure given volume and } \\
\text { temperature }\end{array}$ \\
\hline Dynamatic viscosity & $\begin{aligned} & \eta=M w \cdot 1000 \cdot \exp \left(\sum(\mathrm{Nk}\right. \\
& \cdot(\mathrm{Ak} / \mathrm{T}+\mathrm{Mw} \\
&\cdot \mathrm{Bk})))\end{aligned}$ & $\begin{array}{l}\eta(\mathrm{cp}) \text { is dynamic liquid viscosity; } \\
\mathrm{Mw}(\mathrm{g} / \mathrm{mol}) \text { is molecular weight; } \\
\mathrm{Nk} \text { is is the number of groups } \mathrm{k} \text { in } \\
\text { the molecule; } \mathrm{Ak}, \mathrm{Bk} \text { are model } \\
\text { parameters; and } \mathrm{T}(\mathrm{K}) \text { is } \\
\text { temperature }\end{array}$ & $\begin{array}{l}\text { Kinematic viscosity is defined as } \\
\text { dynamic viscosity divided by } \\
\text { density at a given temperature }\end{array}$ \\
\hline
\end{tabular}




\begin{tabular}{lll}
\hline \multicolumn{1}{c}{ Mixture property } & Model & Parameter \\
\hline $\begin{array}{l}\mathrm{HHV}_{\mathrm{m}} ;-\operatorname{LogLC} 50_{\mathrm{m}} ; \rho_{m} \\
\text { (linear); }\end{array}$ & $P=\sum_{i=1}^{n} x_{i} P_{i}$ & $\begin{array}{l}P_{i} \text { is the property of pure Ideal mixing rule is applied for } \\
\text { component } i ; x_{i} \text { is the mass, these properties } \\
\text { volume or molar fraction of } \\
\text { (linear) }\end{array}$ \\
$\begin{array}{l}\text { component } i \text {; and } n \text { is the number } \\
\text { of compounds in mixture. }\end{array}$
\end{tabular}

\begin{tabular}{|c|c|c|}
\hline Reid Vapor Pressure (RVP) & $R V P=\sum_{i=1}^{n} x_{i} \gamma_{i} P_{i}^{s a t}$ & $\begin{array}{l}P_{i}^{\text {sat }} \text { is the saturated vapor } \\
\text { pressure at temperature } \mathrm{T} \text {; and } \gamma_{i} \text { is } \\
\text { the activity coefficient }\end{array}$ \\
\hline
\end{tabular}

The vapor pressure for blended gasoline is referred as the Reid vapor pressure (RVP), which is defined as the vapor pressure measured at a temperature of $100^{\circ} \mathrm{F}(308 \mathrm{~K})$ in a chamber with a vapor/liquid volume ratio of $4: 1$.

\begin{tabular}{|c|c|c|}
\hline Flash point $\left(\mathrm{T}_{\mathrm{f}}\right)$ & $\sum_{i=1}^{n} \frac{x_{i} \gamma_{i} P_{i}^{\text {sat }}(T)}{P_{i, T f}^{\text {sat }}}-1=0$ & $\begin{array}{l}P_{i}^{\text {sat }} \text { is the saturated vapor } \\
\text { pressure at temperature } \mathrm{T} ; \gamma_{i} \text { is the } \\
\text { activity coefficient; } P_{i, T f}^{\text {sat }} \text { is vapor } \\
\text { pressure of pure compound s at } \\
\text { their flash point. The temperature, } \\
\mathrm{T} \text { is deemed to be the flash point } \\
\text { of the mixture. This property } \\
\text { model requires an iteration to } \\
\text { obtain the flash point of the } \\
\text { mixture }\end{array}$ \\
\hline
\end{tabular}

Flash point $\left(T_{f}\right)$ is defined as the lowest temperature at which the vapor above a liquid can be ignited in air.

The activity coefficient $\left(\gamma_{i}\right)$ is obtained from GE-models such as UNIFAC. $P_{i}^{\text {sat }}(T)$ is the vapor pressure of compound I at temperature $\mathrm{T}$

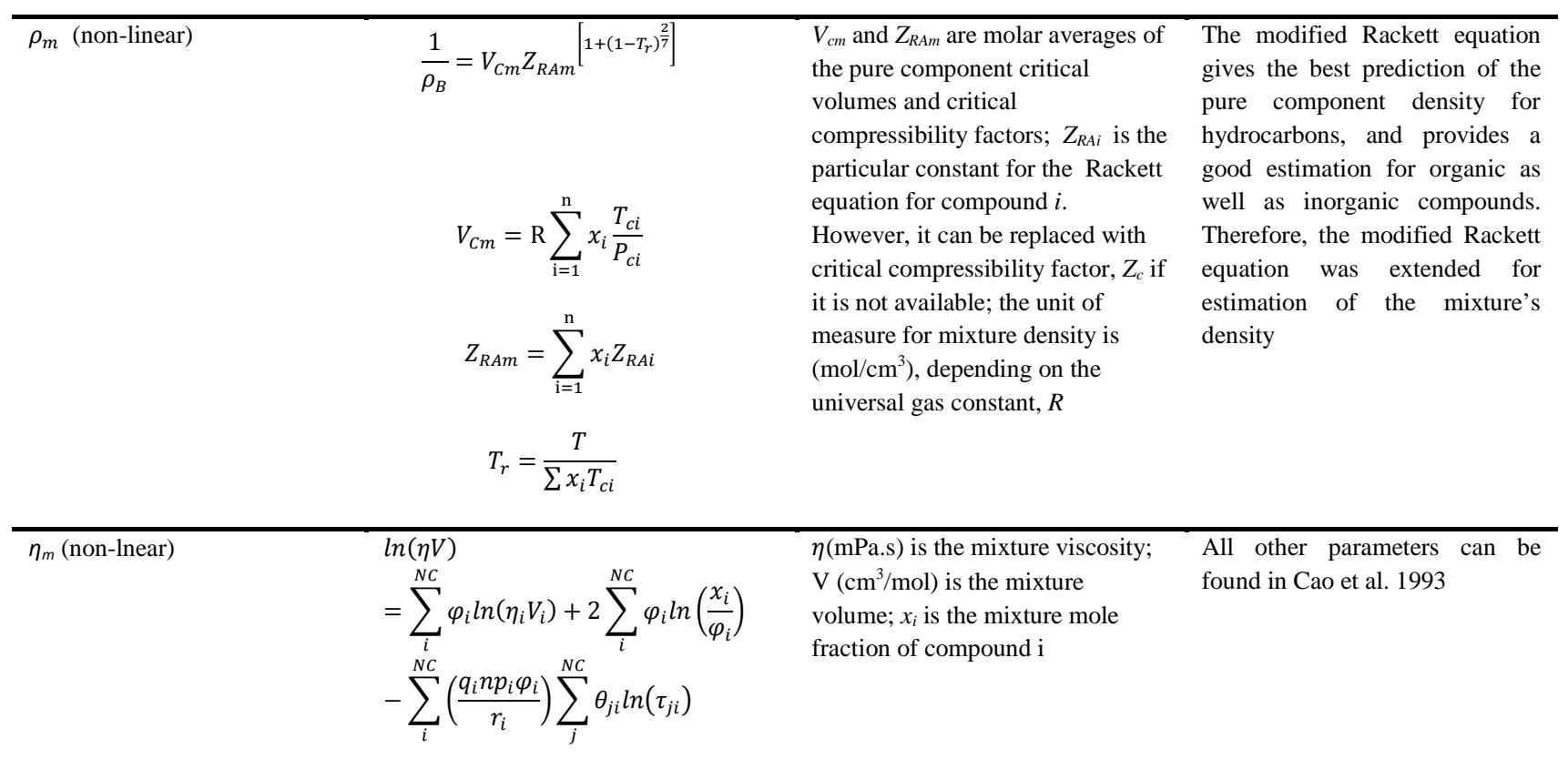

\section{Reference:}

Cao, W., Knudsen K., Fredenslund A., Rasmussen, P. Ind. Eng. Chem. Res. 1993, 32, 2077-2087.

Gross, J., Sadowski, G. Ind. Eng. Chem. Res. 2001, 40, 1244-1260. 


\section{Highlights}

- Gasoline surrogate fuels designed via property driven computer aided model

- The model predicted properties verified via robust experimental techniques

- The experimental assessments helped in improving model predictability

- The developed methodology to be used for the deign of synthetic fuels 